\title{
Educação alimentar e nutricional em escolas estaduais do estado do Tocantins
}

\author{
Júlia Maria Pinheiro, Lídia Silva Braga, Larissa Ferreira Batista, Renata Andrade de Medeiros \\ Moreira
}

\section{Resumo}

O Programa Nacional de Alimentação Escolar (PNAE) prevê a inclusão da educação alimentar e nutricional (EAN) no processo de ensino e aprendizagem abordando alimentação e nutrição e o desenvolvimento de práticas saudáveis de vida, na perspectiva da segurança alimentar e nutricional (SAN). Este é um campo de prática e conhecimento contínua e permanente, intersetorial e multiprofissional, visando a prática autônoma de hábitos alimentares saudáveis. Avaliar a relevância e dificuldades da implementação de atividades de educação alimentar e nutricional nas escolas Estaduais do Tocantins. Estudo transversal realizado nas 423 escolas públicas estaduais do Tocantins cadastradas no PNAE, realizado com os responsáveis pelo programa de cada escola. $\mathrm{O}$ questionário semiestruturado foi enviado por e-mail fornecido pela Secretaria de Educação, e a sensibilização realizada por contato telefônico. O instrumento continha dados sobre as ações de nutrição e EAN desenvolvidas nas escolas abordando a relevância destas e as dificuldades de implementação das mesmas. A avaliação qualitativa se deu por meio de análise de conteúdo, das questões abertas, proposta por Bardin. O projeto foi avaliado pelo Comitê de Ética da Universidade Federal do Tocantins, e os Termos de Consentimento Livre e Esclarecido foram encaminhados juntamente com o questionário. Das $45(10,6 \%)$ escolas estaduais que responderam ao questionário, $43(95,6 \%)$ foram avaliadas, devido estarem completos. As escolas que não realizavam avaliação nutricional e de história de saúde dos escolares justificaram devido à falta de interesse da instituição e a carência de profissionais capacitados. Das que coletavam os utilizavam para a conscientização quanto à alimentação saudável e para adequar o cardápio de acordo com as necessidades detectadas. Quanto à diretriz do PNAE que preconiza a implementação de EAN, os responsáveis que estavam de acordo relataram sua relevância devido permitir a promoção da alimentação saudável, SAN; e minimizar as carências nutricionais. Dentre as vantagens para os alunos levantou-se a promoção da alimentação saudável; a construção de conhecimento sobre alimentação, qualidade de vida e prevenção de doenças; e a melhora da aceitação da alimentação escolar. Para as escolas pontuou-se maior aceitabilidade do cardápio com redução do desperdício, melhoria do rendimento escolar, construção de hábitos alimentares saudáveis pelos alunos, pais/responsáveis. Estas ações na maioria das vezes eram desenvolvidas pelos professores e coordenadores das instituições, e consideravam a formação e conhecimentos destes adequados para executarem a EAN, sendo buscado auxílio na internet e outros meios de comunicação, fornecimento de materiais de apoio e utilização do conhecimento prévio. Porém, foi relatada a necessidade de nutricionistas para a execução das intervenções, devido ser o profissional mais qualificado para executá-las e para realizar capacitação dos educadores e merendeiras. As dificuldades encontradas para a efetivação da EAN nas escolas foram a falta de conscientização e capacitação dos profissionais; de recursos para inserir alimentos saudáveis no cardápio e promover hábitos saudáveis; e deficiência de interação entre a equipe escolar de forma interdisciplinar. Verificou-se que a implementação efetiva das ações de EAN é necessária, inserindo-a na base curricular da escola, porém demanda a capacitação dos profissionais das instituições por nutricionistas das Secretarias de Educação e Saúde.

Descritores: Alimentação escolar; Saúde na escola; Educação alimentar e nutricional. 